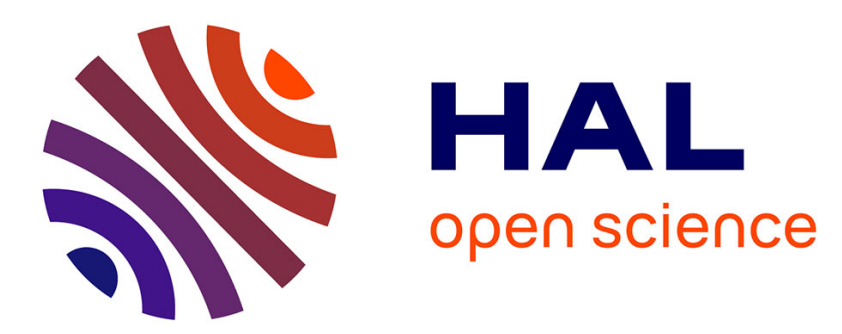

\title{
Characterization of surface properties of chitosan/bentonite composites beads by inverse gas chromatography
}

Soufiane Bensalem, Boualem Hamdi, Sylvie del Confetto, Rachel Calvet

\section{To cite this version:}

Soufiane Bensalem, Boualem Hamdi, Sylvie del Confetto, Rachel Calvet. Characterization of surface properties of chitosan/bentonite composites beads by inverse gas chromatography. International Journal of Biological Macromolecules, 2021, 166, pp.1448-1459. 10.1016/j.ijbiomac.2020.11.024 hal02997266

\section{HAL Id: hal-02997266 \\ https://imt-mines-albi.hal.science/hal-02997266}

Submitted on 7 Dec 2020

HAL is a multi-disciplinary open access archive for the deposit and dissemination of scientific research documents, whether they are published or not. The documents may come from teaching and research institutions in France or abroad, or from public or private research centers.
L'archive ouverte pluridisciplinaire HAL, est destinée au dépôt et à la diffusion de documents scientifiques de niveau recherche, publiés ou non, émanant des établissements d'enseignement et de recherche français ou étrangers, des laboratoires publics ou privés. 


\title{
Characterization of surface properties of chitosan/bentonite composites beads by inverse gas chromatography
}

\author{
Soufiane Bensalem ${ }^{\mathrm{a}, \mathrm{b}, *}$, Boualem Hamdi $^{\mathrm{b}}$, Sylvie Del Confetto ${ }^{\mathrm{c}}$, Rachel Calvet ${ }^{\mathrm{c}}$ \\ a Université Kasdi Merbah-Ouargla, Laboratoire Protection des Ecosystèmes en Zones Arides et Semi Arides, 30000 Ouargla, Algeria

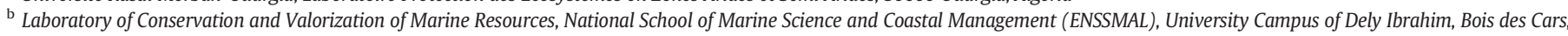 \\ 16320 Cheraga, Algiers, Algeria \\ ' Université de Toulouse, Mines Albi, CNRS UMR 5302, Centre RAPSODEE, Campus Jarlard, F-81013 Albi Cedex 09, France
}

Keywords:

Chitosan/bentonite composites

Inverse gas chromatography

Surface energy

\begin{abstract}
A B S T R A C T
Chitosan/bentonite (CSBt) composites beads were prepared by dropwise of a solution containing chitosan and bentonite to an alkaline $\mathrm{NaOH}$ solution. Fourier Transform Infrared Spectroscopy, X-ray diffraction analysis, Xray photoelectron spectroscopy, XPS and Brunauer-Emmett-Teller BET analysis have been used to provide new insights on the composition and morphology of CSBt composites beads surface. In this study, inverse gas chromatography (IGC) was implemented to characterize physico-chemical properties of CSBt composites surface. IGC at infinite dilution (IGC-ID) was used to understand the effect of CS on dispersive component of the surface energy of the bentonite. The increasing amount of CS leads to significantly decrease of Bt $\gamma_{s}^{d}$ emphasizing the Bt coating with CS. The IGC at finite concentration (IGC-FC) was also implemented allowing us to reach several parameters such as: specific surface area with organic probes and the distribution functions of the adsorption energy sites on the solid surface. In this case, the most significant decreases were observed in the specific surface area obtained with the octane and isopropanol probes. The distribution function of the adsorption energy sites obtained with isopropanol revealed the decrease in the number of the high energy sites with increase of CS/Bt mass ratio.
\end{abstract}

\section{Introduction}

Over the last decades, biopolymer-clay hybrid materials which are known to combine physical and chemical properties of both inorganic and organic materials have gained increasing attention in the areas of science and technology of biopolymer based advanced materials [1-5].

Bentonite (Bt) is an important natural clay material; widely used in many industries, which is made of hydrous aluminosilicates, consisting mostly of montmorillonite, and contains fewer amounts of other clay minerals [6,7]. Bt appears as a promising support material due to its mechanical strength and chemical stability, low cost, and availability [8].

Chitosan (CS), a polycationic biopolymer and waste product from seafood processing industry, is the second most abundant natural polysaccharide after cellulose. Some of the most noted properties of CS are biocompatibility, biodegradability, non-toxicity, adsorption properties, etc. $[9,10]$. CS can be used as an adsorbent to remove dyes [11], and heavy metals [12]. In medical field, chitosan films have been tested as curative wound dressing and as scaffolds for tissue and bone engineering [13]. However, CS has low mechanical properties and become

* Corresponding author at: Université Kasdi Merbah Ouargla, Route de Ghardaia, BP. 511,30 000, Algeria.

E-mail address: soufiane.bensalem@univ-ouargla.dz (S. Bensalem). soluble in acidic media which limits its application as an adsorbent at low $\mathrm{pH}$ [14]. In order to overcome these limitations, physical and chemical modification needs to be carried out on chitosan by its immobilization on a low-cost material such as clay. The combination of clay into polymer backbone was found to lead to improved strength and heat resistance [15].

Because of their functional properties, Chitosan/bentonite composites frequently exhibit remarkably improved mechanical strength; higher thermal stability, and relatively a good surface area [16]. In addition to these characteristics, CSBt composites show the remarkable advantage of exhibiting biodegradability and biocompatibility associated with the biopolymer and can be also an effective adsorbent due to its functional properties to remove pollutants.

Numerous examples found in literature report the application of CS coated Bt composites for adsorption of various contaminants from wastewaters such as heavy metals [17,18] and dyes [19]. CSBt composites have been also used in medical fields [20,21].

It is well known that a surface interaction between CS and Bt induces changes in microstructure morphology and surface chemistry, which are fundamental in adsorption processing, and for drug delivery process.

The changes in surface properties of composite upon biopolymer incorporation, like chemical, energetic and morphological properties could be assessed using inverse gas chromatographic (IGC) analysis. 
Inverse gas chromatography (IGC) is a powerful and sensitive technique to examine surface properties of solids. It is well-established and inexpensive technique for the determination of the influence on solid surface of factors such as milling [22,23], humidity [24], and chemical treatments [25]. The IGC tool has already been implemented in the analysis of solids such as clay [26,27], biopolymers [28,29], bionanocomposites [30-32] and composites [33].

In our previous study [30], CSMMT bionanocomposites based on intercalation of CS in montmorillonite- $\mathrm{Na}^{+}$were prepared, driven by electrostatic interactions between the positively charged amino groups in the CS chains with the negatively charged sites in the clay mineral layers. IGC confirmed that the increase of CS mass ratio in the clay galleries affected the surface properties.

In this paper, CSBt composites beads were prepared with different $\mathrm{CS} / \mathrm{Bt}$ ratios by dropwise addition of liquid slurry containing $\mathrm{CS}$ and $\mathrm{Bt}$ to a $\mathrm{NaOH}$ solution. The composites were characterized by different techniques among which inverse gas chromatography implemented for the first time on these composites beads, either at the infinite dilution conditions (IGC-ID), or at finite concentration conditions (IGC-FC).

\section{Theoretical part}

Inverse gas chromatography (IGC) is a practical method used in the study of the surface properties of finely divided solids [34]. It gives information about a wide number of surface properties of the solid examined.

Depending on the amount of injected probe, the IGC can be divided into two modes: infinite dilution (IGC-ID) [35] and finite concentration (IGC-FC) [36,37].

\subsection{Inverse gas chromatography at infinite dilution}

In IGC-ID, a known volume of gaseous probe molecules (vapor) is injected into a short column packed with the sample at the limit of detector sensitivity. The interactions between probe molecules can be considered as negligible and only the interactions between an isolated probe and the solid surface are considered. The IGC-ID provides different information depending on the chemical nature and geometry of the injected probe. Three following parameters can be determined.

The dispersive component of the surface-free energy of solid materials is measured when n-alkanes are injected as probes at zero coverage conditions (Henry's Law region). This parameter indicates only the dispersive interactions between n-alkanes probes and the solid. The dispersive component of surface energy is determined using Dorris and Gray method [38]. Experimentally, the $\gamma_{s}^{d}$ parameter is determined from the slope of the straight line obtained by the plot of the variation of

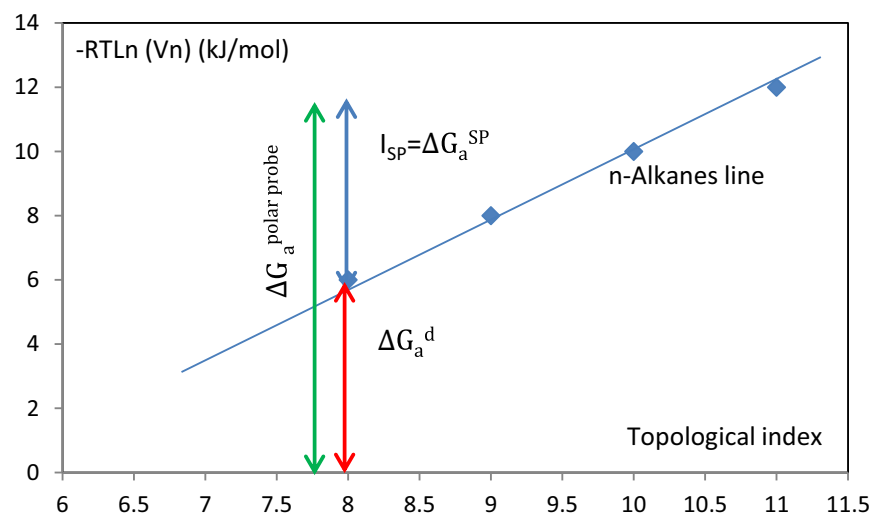

Fig. 1. Determination of the specific interaction parameter ( $\left.I_{S P}\right)$ for polar probes. the adsorption free energy versus the number of carbon atoms for $\mathrm{n}$ alkanes series (Fig. 1) and it's calculated according to Eq. (1)

$\gamma_{s}^{d}=\frac{\left(\Delta G_{a}^{\mathrm{CH}_{2}}\right)^{2}}{4 \mathrm{~N}^{2} a_{\mathrm{CH}_{2}}^{2} \gamma_{\mathrm{CH}_{2}}}$

where $\gamma_{s}^{d}$ is the dispersive component of the surface energy $\left(\mathrm{mJ} / \mathrm{m}^{2}\right)$, $\Delta G_{a}^{\mathrm{CH}_{2}}$ the Gibbs energy adsorption of a methylene group which is the slope of the alkanes line, $\mathrm{N}$ the Avogadro's number, $a_{\mathrm{CH} 2}^{2}$ the molecular area of a $\mathrm{CH}_{2}$ unit $\left(0.06 \mathrm{~nm}^{2}\right), \gamma_{\mathrm{CH} 2}$ its surface energy $\left(35.6 \mathrm{~mJ} / \mathrm{m}^{2}\right.$ at $293 \mathrm{~K})$.

The nanomorphological index is determined by branched or cyclic alkanes injections [39]. This index delivers information about the surface roughness of the solid at the scale of the injected probe.

The nanomorphological index $\mathrm{I}_{\mathrm{M}}\left(\chi_{\mathrm{t}}\right)$ is obtained using of the following Eq. (2)

$\mathrm{I}_{\mathrm{M}}\left(\chi_{\mathrm{t}}\right)=\exp \left(\frac{\delta \Delta G^{M}}{R T}\right)$

$\delta \Delta G^{M}$ is the variation between the representative point of the branched or cyclic alkane and the reference n-alkane straight line, $\chi_{t}$ the topology index proposed by Brendlé, derived from Wiener's topology indices.

The specific component of the surface energy encompasses all categories of interactions such as acid-base and hydrogen bonding, metallic or magnetic interactions except the dispersive ones [39]. It represents the contribution of specific interactions, denoted by $\mathrm{I}_{\mathrm{sp}}$. This parameter can be obtained by the difference between the global free energy of the injected polar probe $\Delta G_{a}$ and the straight line of linear alkane probes (Fig. 1). It is calculated according to the Eq. (3)

$\Delta G_{a}^{S P}=\mathrm{I}_{\mathrm{sp}}=\Delta G_{a}-\Delta G_{a}^{d}$

\subsection{Inverse gas chromatography at finite concentration (IGC-FC)}

In IGC-FC, a small quantity of liquid probe is injected instead of vapor, into a column containing the sample to be analyzed, in order to provide the formation of a probe monolayer on the solid surface.

\subsubsection{The desorption isotherm}

The determination of the desorption isotherm by IGC has been reviewed by Conder and Young [36]. Among the most commonly used methods, "the elution characteristic point" method (ECP) allows the acquisition of the desorption isotherm from the rear front of a unique chromatographic experiment. The first derivative of the isotherm is directly related to the retention time of each point of the chromatogram by Eq. (4)

$\left(\frac{\partial \mathrm{N}}{\partial \mathrm{P}}\right)_{\mathrm{L}, \mathrm{t}_{\mathrm{R}}}=\frac{\mathrm{JD}_{\mathrm{c}}}{\mathrm{RTm}}\left(\mathrm{t}_{\mathrm{R}}-\mathrm{t}_{0}\right)$

where, for a given characteristic point taken on the rear front of the chromatogram, $\mathrm{N}$ is the number of desorbed probe molecules, $\mathrm{P}$ the partial pressure of the probe at the output of the column (directly related to the height of the signal), $t_{r}$ the retention time of the probe, $t_{0}$ the dead retention time of methane (a non-adsorbed molecule), J the James and Martin's coefficient, $D_{C}$ the corrected flow rate, $m$ the mass of the solid in the column, $\mathrm{L}$ the column length, $\mathrm{R}$ the universal gas constant and $\mathrm{T}$ the oven temperature.

The integration of Eq. (4) gives access to the desorption isotherm. In IGC-FC, the specific surface areas ( $\left.\mathrm{a}_{\mathrm{BET}}\right)$ and the BET constants $\left(\mathrm{C}_{\mathrm{BET}}\right)$ are determined according to the Inverse Langmuir equation (Eq. (5)) derived from the BET equation (Eq. (6)) for different organic probes [37]. 
$\mathrm{N} \prime=\mathrm{N}_{\mathrm{m}} \frac{\mathrm{C}_{\mathrm{BET}} \cdot \mathrm{P}^{\prime}}{1+\mathrm{C}_{\mathrm{BET}} \cdot \mathrm{P}^{\prime}}$

$\frac{\mathrm{N}}{\mathrm{N}_{\mathrm{m}}}=\frac{\mathrm{C}_{\mathrm{BET}} \cdot \mathrm{X}}{(1-\mathrm{X})\left(1-\mathrm{X}+\mathrm{C}_{\mathrm{BET}} \cdot \mathrm{X}\right)}$

where $\mathrm{N}$ is the amount of molecules adsorbed at a given relative pressure $\mathrm{x}=\mathrm{P} / \mathrm{P}_{0}, \mathrm{~N}_{\mathrm{m}}$ the monolayer capacity, the amount of gas adsorbed required to cover the solid surface with a single monolayer at standard temperature and pressure, $\mathrm{N}^{\prime}$ and $\mathrm{P}^{\prime}$ are respectively the amount of adsorbed probe and the equilibrium pressure of the probe corrected for the multilayer adsorption $\left(\mathrm{N}^{\prime}=\mathrm{N}(1-\mathrm{x})\right.$ and $\left.\mathrm{P}^{\prime}=\mathrm{x} /(1-\mathrm{x})\right)$.

The sites having a high energy of interaction with the injected probe can be evaluated from the amounts of probes not eluted after the signal returns to the baseline. In order to desorb the probes "irreversibly" adsorbed at the analysis temperature, the oven temperature is increased until the conditioning temperature and a second peak appears called the thermodesorption peak. The ratio of the thermodesorption peak area onto the total area of the chromatogram allows to calculate the irreversibility index $\mathrm{I}_{\text {irr }}$ indicating the amount of irreversibly adsorbed probe on the surface at the analysis temperature corresponding to the amount of high energy sites:

$\mathrm{I}_{\mathrm{irr}}=\mathrm{S}_{\mathrm{th}} /\left(\mathrm{S}_{\mathrm{rv}}+\mathrm{S}_{\mathrm{th}}\right)$

where $S_{\mathrm{rv}}$ is the surface of the main chromatographic peak and $S_{\text {th }}$ the surface corresponding to the thermodesorption peak.

\subsubsection{The surface heterogeneity}

The estimation of surface heterogeneity is described by a distribution function (DFRJ) which corresponding to the relative abundance of each type of domain having the same characteristic energy of interaction.

The calculation of the distribution functions DFRJ is based on a physical patchwork model considering that the global isotherm can be considered as the sum of local isotherms of adsorption on isoenergetic domains.

$\mathrm{N}(\mathrm{P}, \mathrm{T})=\mathrm{N}_{0} \int_{\varepsilon_{\min }^{i}}^{\varepsilon_{\max }^{i}} \theta\left(\varepsilon^{i}, \mathrm{P}, \mathrm{T}\right) \cdot \chi\left(\varepsilon^{i}\right) \cdot d \varepsilon^{i}$

where $\mathrm{N}(\mathrm{P}, \mathrm{T})$ is the measured adsorption isotherm at pressure $\mathrm{P}$ and absolute temperature $\mathrm{T}, \mathrm{N}_{0}$ is the total number of adsorption sites on the studied heterogeneous surface, $\theta\left(\varepsilon^{i}, \mathrm{P}, \mathrm{T}\right)$ is the local adsorption isotherm (generally the Langmuir's isotherm) corresponding to adsorption sites having the same characteristic adsorption energy $\varepsilon^{i}, \chi\left(\varepsilon^{i}\right)$ is the number of sites exhibiting the same interaction energy $\varepsilon$ and is called distribution function of the adsorption energies, and $\varepsilon_{\mathrm{min}}^{i}$ and $\varepsilon_{\max }^{i}$ the lowest and highest values of the adsorption energy.

The integral equation is easy to solve [37], it leads to the DFCA (distribution function in the condensation approximation), but this approximation is acceptable only for a temperature analysis close to the absolute zero. However, IGC-FC analyses are generally made above room temperature and the condensation approximation is no more correct. Rudzinski [40] proposed another method allowing the calculation of the so called DFRJ (distribution function in the Rudzinski-Jagiello model) through a limited development of the even derivatives of the DFCA, corrected for the lateral interaction energy.

$\chi \mathrm{CA}(\varepsilon)=\frac{\mathrm{P}^{\prime}}{\mathrm{RT}} \frac{d}{d \mathrm{P}^{\prime}}\left[\frac{\mathrm{N}^{\prime}\left(\mathrm{P}^{\prime}\right)}{\mathrm{N}_{0}}\right]$

where $\mathrm{N}^{\prime}$ and $\mathrm{P}^{\prime}$ are respectively the amount of adsorbed probe and the equilibrium pressure of the probe corrected for the multilayer adsorption.
Balard [22,37] described a signal treatment method based on Fourier's transform to calculate the FDRJ up to the order 4.

$\chi(\varepsilon)=\sum_{j=0}^{+\infty}(R T)^{2 j} b_{2 J} \chi_{C A}^{2 j}(\varepsilon)$ With $b_{0}=1$ and $b_{2 j}=(-1)^{j} \frac{\pi^{2 j}}{(2 j+1) !}(10)$

The surface heterogeneity can be quantified by the surface heterogeneity index, $\mathrm{I}_{\text {hete, }}$ expressed in Eq. 11:

$I_{\text {hete }}=100 \frac{A_{\text {exp }}-A_{\text {homo }}}{A_{\exp }}$

where $A_{\exp }$ is the area under the experimental DF and $A_{\text {homo }}$ is that under the homogeneous DF.

This index allows the comparison of the computed DF with the DF describing a homogeneous surface that fits the left descending branch of the experimental DF towards the lowest interaction energies.

Desorption isotherm and adsorption energy distribution functions were computed using a software from the Adscientis Society (Wittelsheim, France).

\section{Materials and methods}

\subsection{Materials}

CS was purchased from France Chitine Society (Degree of Deacetylation $=80 \%$ determined by ${ }^{1} \mathrm{H}$ NMR and its average molecular weight, 293,000 g/mol, determined by gel permeation chromatography). Bt powder with a particle size of 40-100 mesh was acquired from the Maghnia deposit (western of Algeria), provided from the ENOF Company (Algeria), and was used without further purification. The probes employed for IGC were n-alkanes: n-pentane (C5), nhexane (C6), n-heptane (C7), n-octane (C8), n-nonane (C9); a cyclic alkane cycloheptane (Cy7); and polar probes (dichloromethane $\mathrm{CH}_{2} \mathrm{Cl}_{2}$, acetone and isopropanol (IP)). These probes, provided from Aldrich had chromatographic grade (>99\%) purity. All other chemicals and reagents used were of analytical grade and have been used as received.

\subsection{Methods}

\subsubsection{Preparation of chitosan coated bentonite CSBt beads}

CS solutions were prepared by dissolving $0.5,2.5$ and $5 \mathrm{~g}$ of CS in $5 \%$ (v:v) acetic acid:water solution at $403 \mathrm{~K}$ for $12 \mathrm{~h}$. Bt ( $5 \mathrm{~g}$ ) was dispersed and stirring in $100 \mathrm{~mL}$ distilled water for $5 \mathrm{~h}$ at $298 \mathrm{~K}$. Then the $\mathrm{CS}$ solution was added to the Bt suspension and stirring at $333 \mathrm{~K}$ for $24 \mathrm{~h}$ to obtain the modified Bt with CS mass ratios of $0.1 / 1,0.5 / 1,1 / 1$, respectively. The mixtures CSBt were then added dropwise into a $1 \mathrm{~L}(1 \mathrm{M}) \mathrm{NaOH}$ solution under continuous stirring at $150 \mathrm{rpm}$ for $4 \mathrm{~h}$. At the end of the reaction, the composites CSBt were separated from the aqueous phase by simple filtration, washed with distilled water and dried at $333 \mathrm{~K}$ for $24 \mathrm{~h}$. After dried, the composites were manually ground to pass through 200-400 mesh sieves.

\subsubsection{Characterization methods}

The surface functional groups of the composite were identified by transmittance on a $\mathrm{KBr}$ disc using FTIR (ThermoFisher Scientific Company), over the range $4000-400 \mathrm{~cm}^{-1}$, The structure of the composite was verified by X-ray diffraction method using a PANanalyticalX'Pert Pro MPD diffractometer (Bragg-Brentano set-up). Diffraction data were acquired by exposing the powders samples to $\mathrm{Cu}-\mathrm{K} \alpha$ radiation, which has a wavelength of $1.5418 \AA$. The data were collected over a range of $5^{\circ}-25^{\circ} 2 \theta$ with a step size of $0.03^{\circ} 2 \theta$ and a nominal time per step of $100 \mathrm{~s}$, using the scanning X'Celerator detector. Samples morphology was investigated using an environmental scanning electron microscope Philips XL30 ESEM FEG operating at $8 \mathrm{kV}$. The chemical nature of surface was identified by X-ray photoelectron spectroscopy (XPS) using 
KRATOS Axis Ultra X-ray photoelectron spectrometer (Kratos Analytical, Manchester, UK) equipped with a monochromated Al K $\alpha$ X-ray source ( $\mathrm{h} v=1486.6 \mathrm{eV}$ ) operating at $120 \mathrm{~W}$. Textural properties were determined by $\mathrm{N}_{2}$ physisorption at $77 \mathrm{~K}$ with a 3Flex apparatus from Micromeritic company applying the BET model. The samples were out gassed at $303 \mathrm{~K}$ for $24 \mathrm{~h}$.

For IGC measurements, instruments from Agilent (7890 A and 6890 models) were used, with a flame ionization detector (FID). Helium was used as the carrier gas with a $30 \mathrm{~mL} / \mathrm{min}$ flow rate measured with an electronic flowmeter (Flow 500-Agilent). The injector and detector temperatures were 403 and $473 \mathrm{~K}$, respectively. The columns were stainless steel tubes of $6.35 \mathrm{~mm}$ inside diameter and $15-50 \mathrm{~cm}$ length, filled with a sample mass between 0.12 and $1.15 \mathrm{~g}$. The conditioning temperature was taken equal to $403 \mathrm{~K}$ after a study made on the effect of temperature on the surface properties of the CS, Bt and CSBt. This temperature does not alter the surface properties of the solid.

The IGC-ID study was done with an oven temperature of $333 \mathrm{~K}$ for CS analysis and $383 \mathrm{~K}$ for $\mathrm{Bt}$ and composites. The probes used were linear, cyclic alkanes and polar ones (dichloromethane and acetone).

The IGC-FC measurements were performed at an oven temperature of $333 \mathrm{~K}$ for n-octane (C8) probe and $313 \mathrm{~K}$ for isopropanol (IP).

\section{Results and discussion}

4.1. Structure analysis by scanning electron microscopy (SEM)

The SEM micrographs of CS, Bt and CSBt composites are displayed Fig. 2. CS presents a sheet-like structure. The morphology of Bt shows small particles agglomerates with irregular forms and each particle exhibits a lamellar structure. The structure of CSBt is similar to that of Bt, with small particles agglomerates with a heterogeneous surface. SEM does not allow to conclude on a modification of Bt surface with CS.

\subsection{FTIR analysis}

The FTIR spectra for Bt, CS and CSBt composites are shown in Fig. 3. The spectra of CSBt composites, with different mass ratios CS/Bt show the combination of the characteristic absorption bands of CS and Bt.

The absorption band at $3612 \mathrm{~cm}^{-1}$ corresponding to the elongation vibrations of the free $\mathrm{OH}$ groups of water in $\mathrm{Bt}$ is hidden by that of the same OH groups of CS at $3419 \mathrm{~cm}^{-1}$ in CSBt $0.5 / 1$ and CSBt $1 / 1$ composites, which shows the combination of CS with Bt. Peaks around 2900 and $2800 \mathrm{~cm}^{-1}$ for $\mathrm{CS}, \mathrm{Bt}$, and composites, represent the $\mathrm{C}-\mathrm{H}$ group
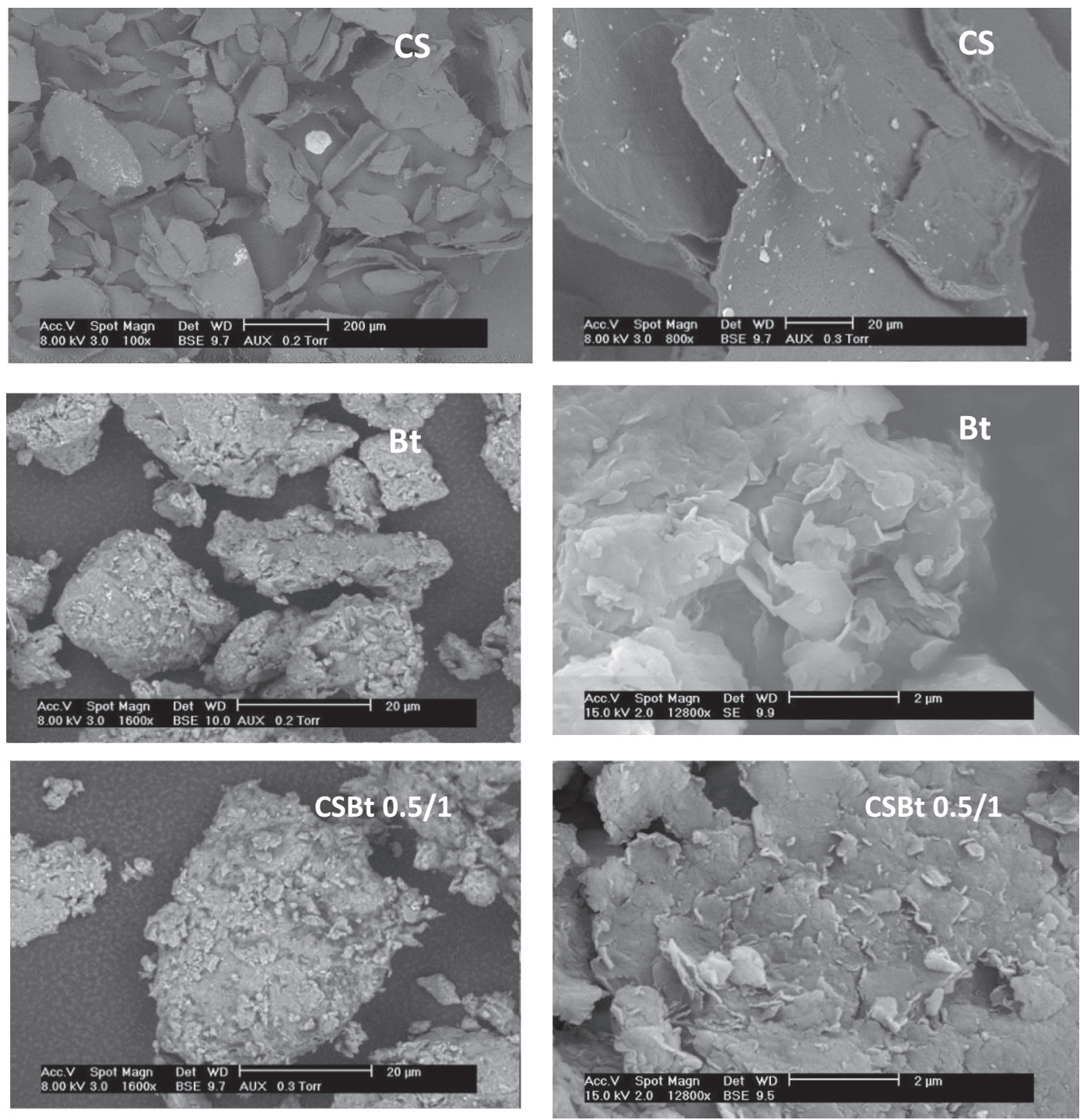

Fig. 2. SEM micrographs of CS, Bt and CSBt. 


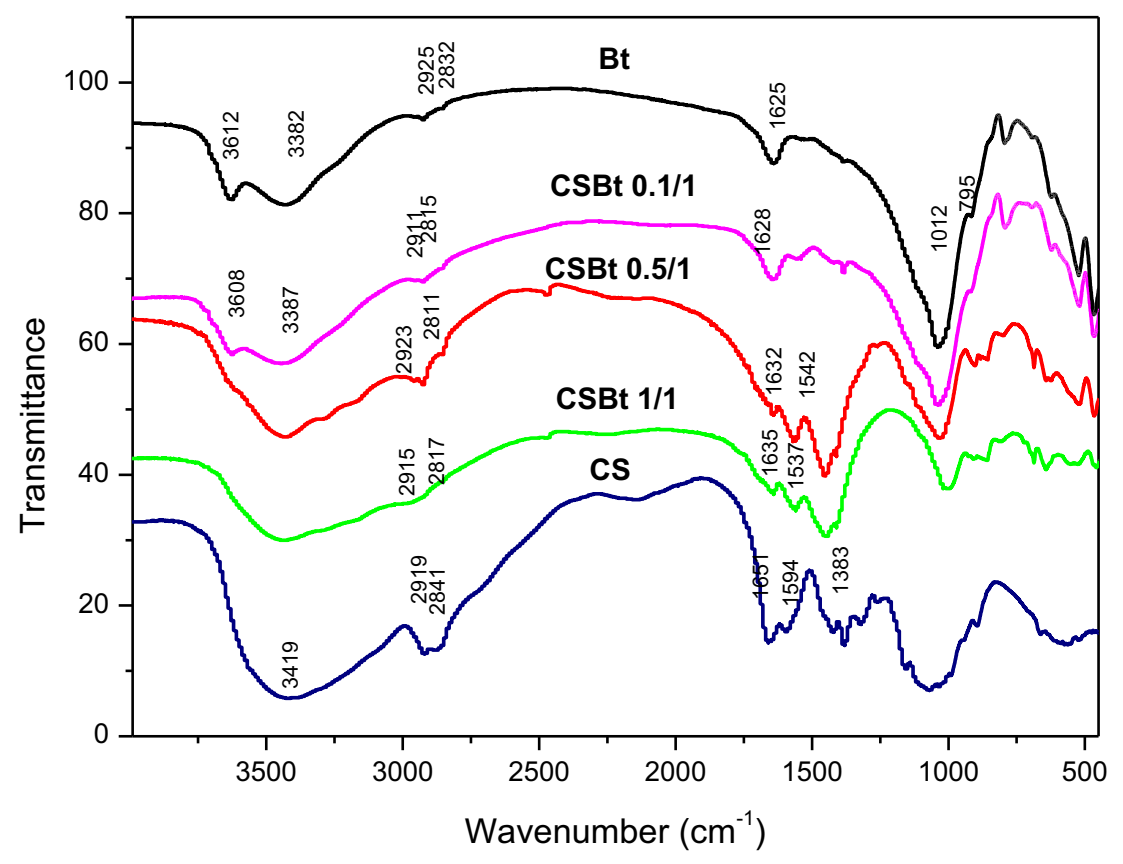

Fig. 3. FTIR spectra of Bt, CS and CSBt composites.

vibrations $[41,42]$. These $\mathrm{C}-\mathrm{H}$ peaks, non-specific to either compound, cannot be exploited to conclude on the interactions between CS and Bt. A sharp and intense band observed at $1625 \mathrm{~cm}^{-1}$ in Bt is attributed to the asymmetric $\mathrm{OH}$ vibration (deformation mode) of water and is a structural part of the mineral. This peak is shifted to 1628,1632 and $1635 \mathrm{~cm}^{-1}$ for CSBt $0.1 / 1,0.5 / 1$ and $1 / 1$ respectively, and its intensity decreases, indicating that CS impregnation affects the surface of $\mathrm{Bt}$, the structure of aluminosilicate nanosheets.

The frequency of vibrational band at $1594 \mathrm{~cm}^{-1}$ in the starting CS, which corresponds to the deformation vibration of the amine group, is shifted towards lower frequency in CSBt composite (1537and $1542 \mathrm{~cm}^{-1}$, for CSBt $1 / 1$ and CSBt $0.5 / 1$ respectively), indicating a strong interaction between CS and Bt [43]. The intense peak observed at $1012 \mathrm{~cm}^{-1}$ in Bt which corresponds to the valence vibrations of the $\mathrm{Si}-\mathrm{O}$ bond, decreases in intensity in the CSBt composites, another evidence of the impact of CS impregnation on surface properties.

\subsection{Analysis by X-ray diffraction}

The X-ray analysis of the CS, Bt and CSBt are given in Fig. 4. The Bt XRD pattern shows the presence of smectite clay at $7.59^{\circ}(2 \theta)$ reported at $6.92^{\circ}(2 \theta)$ by Foletto et al. [44], which is the major constituent of Bt, quartz $\left(19.72^{\circ}\right)$ and kaolinite $\left(21.93^{\circ}\right)$ [45]. CS exhibits a typical peak at $20.05^{\circ}(2 \theta)$. This broad peak indicates the existence of an amorphous

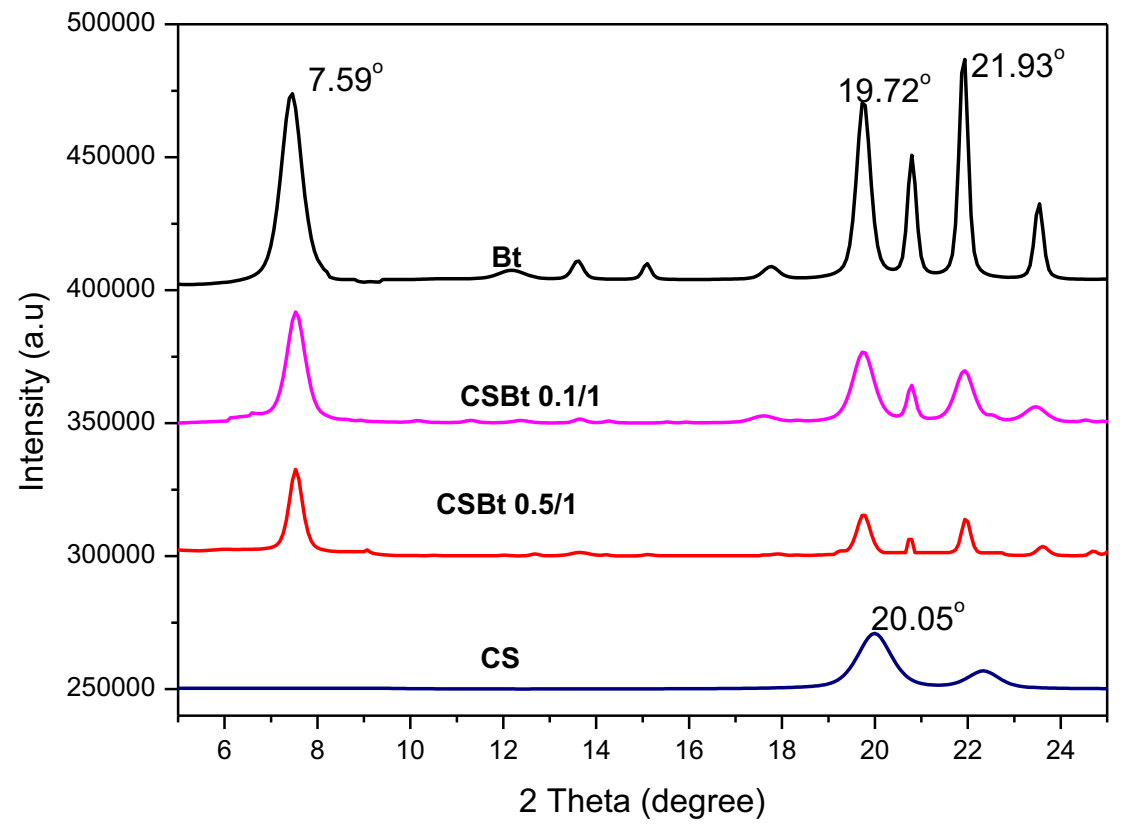

Fig. 4. XRD diffractograms of Bt, CS and CSBt composites. 
structure [46]. In $0.1 / 1$ and $0.5 / 1 \mathrm{CSBt}$, the peak observed at $7.59^{\circ}$ in $\mathrm{Bt}$ and corresponding to a d001 spacing is not shifted towards lower diffraction angle. This indicates that CS molecules did not intercalated in layers silicate of clay. Indeed, the interactions of CS with Bt distort the crystalline structure of Bt [19] and shifts the position of this peak. The peaks at $19.72^{\circ}$ and $21.93^{\circ}(2 \theta)$ corresponding to the various components of the Bt become less intense $(0.5 / 1 \mathrm{CSBt})$ after the introduction of CS. XRD emphasizes crystalline structure change of the intrinsic lattice arrangement of the silicate layers with the incorporation of CS in the Bt. The same results were obtained in the work of Dalida et al. [17].

\subsection{Analysis by X-ray photoelectron spectroscopy (XPS)}

The main elements of CS, Bt, and CSBt composites were analyzed using XPS, and the chemical composition and changes of CSBt composites with increase of CS/Bt mass ratio were investigated (Fig. 5).

Fig. 5 displays low resolution survey spectra. The Bt survey spectrum exhibits Na1s (1072 eV), O1s (532 eV), MgKLL (348 eV), C1s (284 eV), Si2s (150 eV), Al2s (118 eV), Si2p (102 eV), Al2p (74 eV) and Mg2p $(49 \mathrm{eV})$ from the aluminosilicates clay.

The XPS spectrum of CS is dominated by the carbon and oxygen which occur at about 284 and $532 \mathrm{eV}$, respectively, with a small peak of nitrogen at $398 \mathrm{eV}$ and some impurities.

The composites CSBt exhibit a much sharper C1s peak, and a low N1s peak characteristic of the CS. In addition, the composites CSBt exhibit a quantum jump in the $\mathrm{C} 1 \mathrm{~s} / \mathrm{O} 1 \mathrm{~s}$ and $\mathrm{N} 1 \mathrm{~s} / \mathrm{O} 1 \mathrm{~s}$ intensity ratios, compared to pristine Bt, which is an indication of CS-rich surface.

The surface chemical composition as deduced from the narrow XPS regions is reported in Table 1.

All relative concentrations of main elements of $\mathrm{Bt}(\mathrm{Si}, \mathrm{Al}, \mathrm{O})$ decrease upon CS incorporation. Simultaneously, C and N major elements of CS increase with increase of mass ratio CS/Bt. CS is gradually loaded at the surface on the composite CSBt as initial CS concentration increases.

The assignment of deconvoluted high resolution XPS spectrum of C1s peak in CS, Bt and CSBt 0.5/1 is displayed in Fig. 6.
Table 1

Surface chemical composition of Bt, CS and CSBt composites obtained by XPS (Chemical composition is in atomic percentage (at.\%)).

\begin{tabular}{lllllrlllll}
\hline & $\mathrm{O}$ & $\mathrm{N}$ & \multicolumn{1}{c}{$\mathrm{C}$} & $\mathrm{Ca}$ & $\mathrm{Si}$ & $\mathrm{Al}$ & $\mathrm{Mg}$ & $\mathrm{Na}$ & $\mathrm{K}$ & $\mathrm{Fe}$ \\
\hline Bt & 49.59 & - & 8.69 & 1.35 & 25.41 & 9.84 & 2.28 & 1.5 & 0.39 & 0.95 \\
CS & 38.08 & 5.67 & 52.80 & 1.61 & 0.86 & - & 0.98 & - & - & - \\
CSBt $0.1 / 1$ & 50.10 & 0.49 & 11.67 & 1.55 & 23.46 & 9.54 & 0.55 & 1.52 & 0.49 & 0.63 \\
CSBt $0.5 / 1$ & 41.70 & 1.82 & 35.96 & 1.14 & 13.75 & 3.12 & 0.32 & 1.30 & 0.25 & 0.64 \\
CSBt $1 / 1$ & 40.63 & 2.87 & 37.49 & 1.72 & 9.62 & 2.99 & 1.10 & 2.59 & 0.45 & 0.54 \\
\hline
\end{tabular}

The C1s peak in CS (Fig. 6a) sample can be deconvoluted into four components at binding energies of 284.6, 286.1,287.8, and $289.3 \mathrm{eV}$ corresponding to the following groups: $\mathrm{C} 1(\mathrm{C}-\mathrm{H} / \mathrm{C}-\mathrm{C}), \mathrm{C} 2(\mathrm{C}-\mathrm{O} / \mathrm{C}-\mathrm{N} /$ $\mathrm{C}-\mathrm{O}-\mathrm{C}), \mathrm{C} 3(\mathrm{O}-\mathrm{C}-\mathrm{O})(\mathrm{C}=\mathrm{O})$ and $\mathrm{C} 4(\mathrm{~N}-\mathrm{C}=\mathrm{O})[47]$.

The deconvolution of the $\mathrm{C} 1 \mathrm{~s}$ peak in $\mathrm{Bt}$ (Fig. $6 \mathrm{~b}$ ) leads also to four groups $\mathrm{C} 1(\mathrm{C}-\mathrm{H} /(\mathrm{C}-\mathrm{C}), \mathrm{C} 2(\mathrm{C}-\mathrm{O} / \mathrm{C}-\mathrm{OH}), \mathrm{C} 3(\mathrm{C}=\mathrm{O})$ and $\mathrm{C} 4(\mathrm{C}-\mathrm{O})$ in $\mathrm{CO}_{3}^{2-}$ at $284.60,286.15,287.35$ and $289.37 \mathrm{eV}$, respectively.

Likewise, the C1s peak of CSBt 0.5/1 (Fig. 6c) reveals also four components at 284.48, 285.98, 287.13, and $289.23 \mathrm{eV}$ which are assigned to $\mathrm{C} 1(\mathrm{C}-\mathrm{H} / \mathrm{C}-\mathrm{C}), \mathrm{C} 2(\mathrm{C}-\mathrm{O} / \mathrm{C}-\mathrm{N} / \mathrm{C}-\mathrm{O}-\mathrm{C} / \mathrm{C}-\mathrm{OH}), \mathrm{C} 3(\mathrm{C}=\mathrm{O})$ and

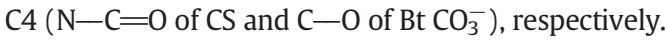

It is remarkable that the $\mathrm{C} 1 \mathrm{~s}$ spectrum of the CSBt composite (Fig. 6c) is so different from that of the pristine Bt (Fig. 5b).

The N1s high resolution regions of CS (Fig. 6d) are fitted with two components. The peak at $399.9 \mathrm{eV}$ was assigned to $\mathrm{NH}_{2} \mathrm{C}$ chemical bonds [48], while the peak at $402.1 \mathrm{eV}$ was assigned to amino groups in the ammonium form $\mathrm{NH}_{3}^{+}$[47].

In the CSBt 0.5/1 composite (Fig. 6e), the peak assigned to the $\mathrm{NH}_{3}^{+}$ ammonium groups has disappeared; this fact testifies that the alkaline $\mathrm{NaOH}$ treatment converts protonated groups into neutral groups in the surface of composites according to the results already observed by Diosa, Poveda-Jaramillo, Ramirez-Rodríguez and Mesa [49]. Indeed, they worked on the preparation of a biohybrid composite based on CS and silica, they found, at basic $\mathrm{pH}(\mathrm{pH}=8)$, that the main contribution to the N1s signal came from neutral (non-protonated) nitrogen of

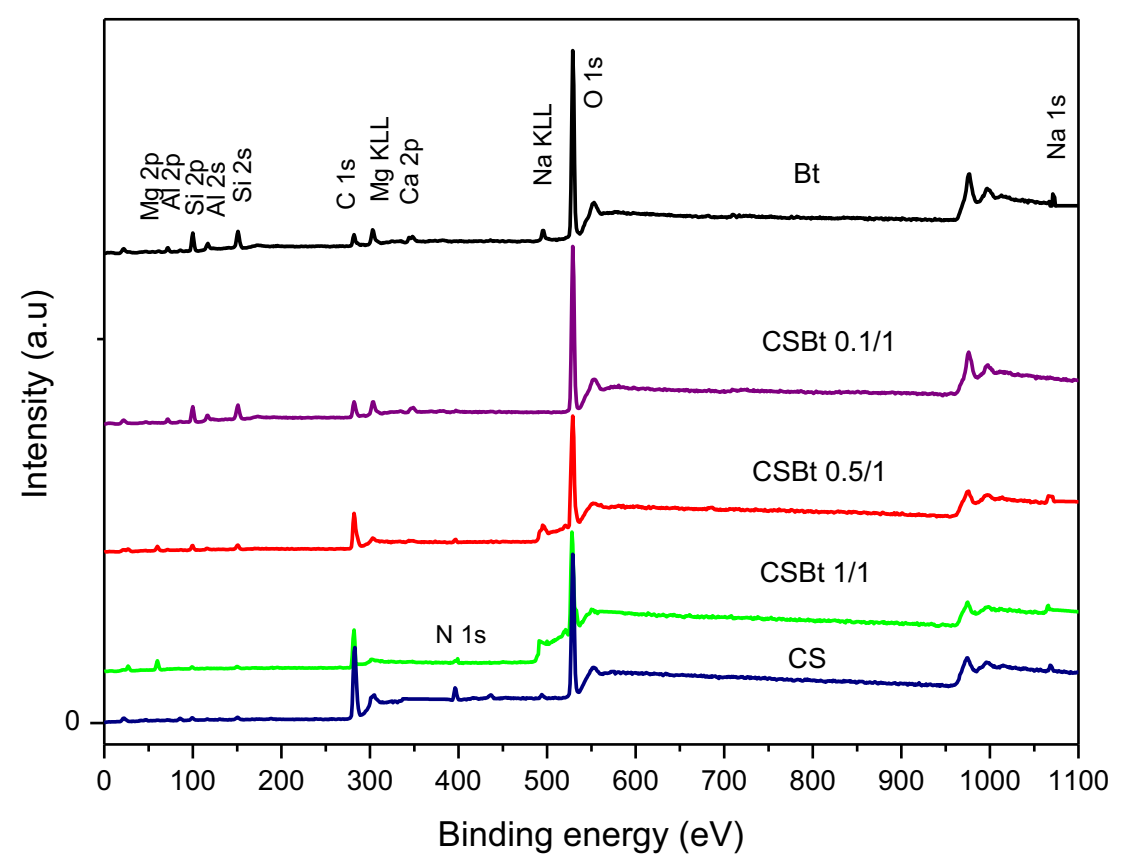

Fig. 5. XPS survey spectra of Bt, CS and CSBt composites. 

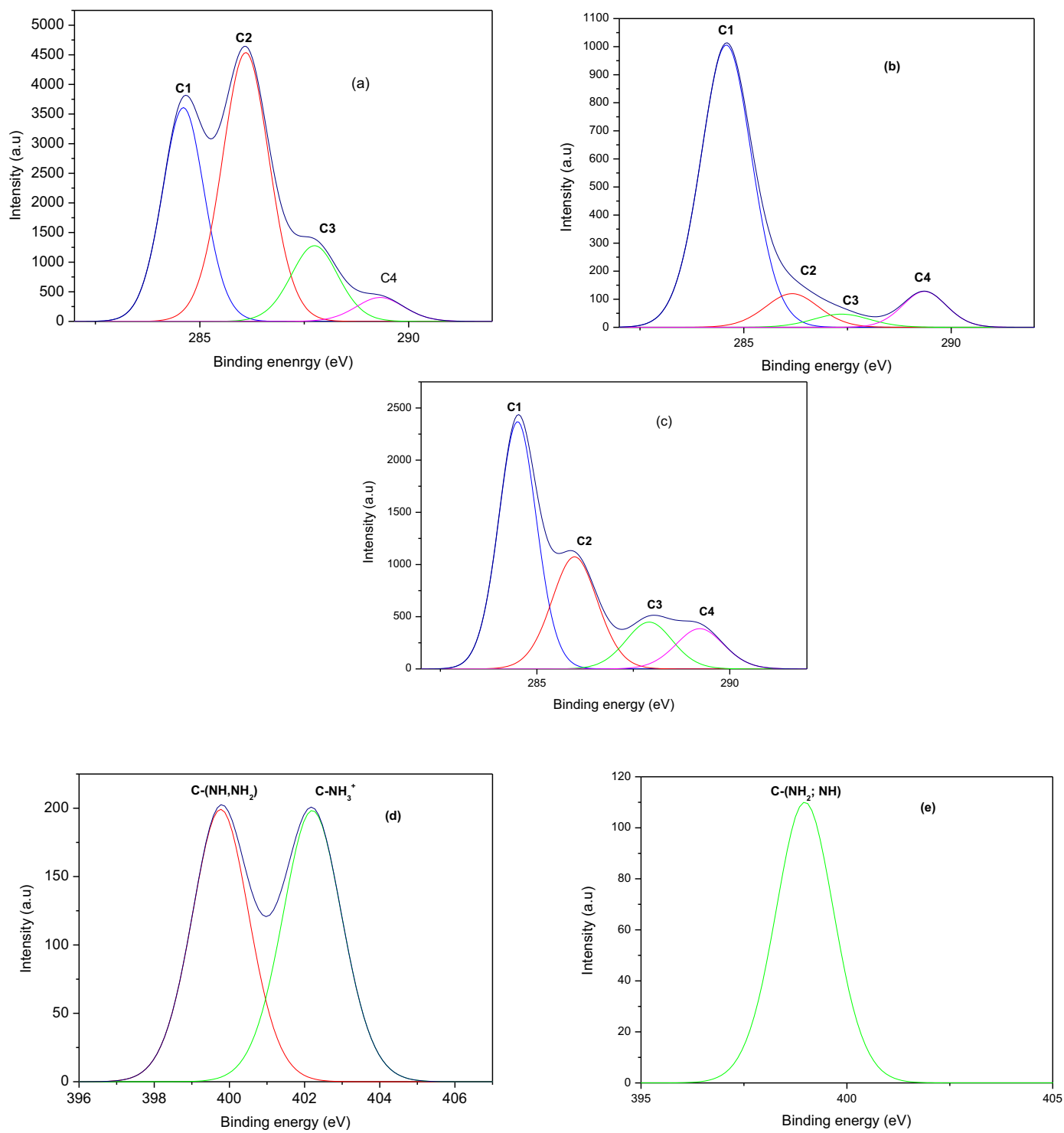

Fig. 6. C1s and N1s high resolution regions (XPS) of Bt, CS and CSBt (a: C1s of CS, b: C1s of Bt, c: C1s of 0.5/1 CSBt, d: N1s of CS and e: N1s of CSBt 0.5/1).

amine/amide groups of CS and the protonated amine groups disappear in $\mathrm{CS} /$ silica composite.

\subsection{BET surface analysis}

The $\mathrm{N}_{2}$ adsorption-desorption measurement was conducted to study specific surface areas and porosity of CSBt composites compared to that of Bt. Whatever the solid (Bt or composites), the N2 isotherms plots (Fig. 7) show typical type IIb isotherms according to the IUPAC classification with type $\mathrm{H} 3$ hysteresis loop representing a sheet structure, non-rigid which swells under capillary condensation. The hysteresis of CSBt $0.1 / 1$ composite is much wider than that of CSBt $1 / 1$. It is reasonable to assume that precipitation and coating by CS on Bt sheets and surface limit the Bt swelling and tend to suppress hysteresis in CSBt $1 / 1$ composite.

The values of specific surface area $\left(\mathrm{a}_{\mathrm{BET}}\right)$ obtained by exploiting adsorption isotherms of $\mathrm{N}_{2}$ at $77 \mathrm{~K}$ are represented in Table 2.

The specific surface areas decrease from $74.4 \mathrm{~m}^{2} / \mathrm{g}$ for Bt to $5.4 \mathrm{~m}^{2} / \mathrm{g}$ after CS incorporation. This fact can be attributed to a covering of the surface of Bt with CS, characterized by a non-porous surface. A similar change was obtained for the preparation of chitosan/vermiculite composites [50] and chitosan/montmorillonite bionanocomposites [30].

\subsection{Surface properties by inverse gas chromatography (IGC)}

\subsubsection{IGC at infinite dilution (IGC-ID)}

The values of $\gamma_{s}^{d}, \mathrm{I}_{\mathrm{M}}(\chi \mathrm{t})$ and $\mathrm{I}_{\mathrm{sp}}$ of the studied samples are presented in Table 3. The value of $\gamma_{s}^{d}$ obtained for CS at $333 \mathrm{~K}$ is typical of biopolymers characterized by a low dispersive surface energy. Indeed, this value $\left(46 \mathrm{~mJ} / \mathrm{m}^{2}\right)$ is identical to those obtained in the works of Belgacem, Blayo and Gandini [51] namely $45 \mathrm{~mJ} / \mathrm{m}^{2}$ for CS at $323 \mathrm{~K}$, or by Shi, Zhao, Jia and Wang [28] namely $46 \mathrm{~mJ} / \mathrm{m}^{2}$ for chitin at $333 \mathrm{~K}$.

Conversely, the value obtained for Bt $\left(174 \mathrm{~mJ} / \mathrm{m}^{2}\right)$ indicates a high energy material. Such high values were reported for different clay materials by Cordeiro, Silva, Gomes and Rocha [52] (291.3 mJ/m² for bentonite at $393 \mathrm{~K}$ ) and Picard, Gauthier, Gérard and Espuche [53] (approximately $120 \mathrm{~mJ} / \mathrm{m}^{2}$, at $373 \mathrm{~K}$ for montmorillonite). This high energy is attributed to the insertion of linear alkanes into the space between sheets of phyllosilicate [26,54].

For CSBt beads, the values of $\gamma_{s}^{d}$ decrease from $112 \mathrm{~mJ} / \mathrm{m}^{2}$ to $49.1 \mathrm{~mJ} /$ $\mathrm{m}^{2}$, as the CS/Bt increases. This behavior could be explained by the 


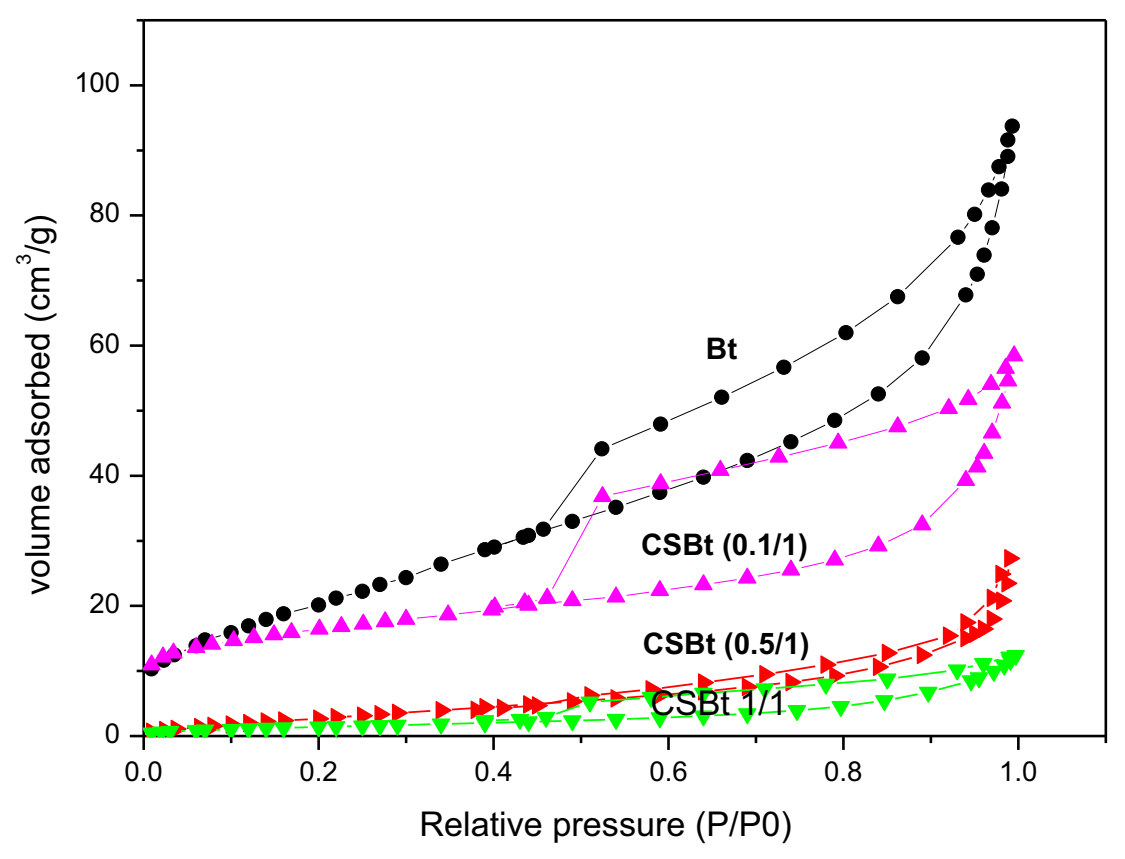

Fig. 7. Nitrogen adsorption-desorption isotherms of Bt and CSBt composites.

Table 2

Values of specific surface areas ( $\mathrm{a}_{\mathrm{BET}}$ ), for Bt, CS and CSBt composite.

\begin{tabular}{lc}
\hline Sample & $\mathrm{a}_{\text {BET }}\left(\mathrm{m}^{2} / \mathrm{g}\right)$ \\
\hline Bt & 74.4 \\
CSBt $0.1 / 1$ & 58.0 \\
CSBt $0.5 / 1$ & 12.5 \\
CSBt $1 / 1$ & 5.4 \\
CS & 4.1 \\
\hline
\end{tabular}

Table 3

Values of $\gamma_{s}^{d}, \mathrm{I}_{\mathrm{M}}(\chi \mathrm{t})$ and $\mathrm{I}_{\mathrm{sp}}$ of the studied samples.

\begin{tabular}{lllll}
\hline & $\gamma_{\mathrm{s}}^{\mathrm{d}}\left(\mathrm{mJ} / \mathrm{m}^{2}\right)$ & $\mathrm{I}_{\mathrm{M}}(\chi \mathrm{t}) \mathrm{Cy} 7$ & $\mathrm{I}_{\mathrm{sp}} \mathrm{CH}_{2} \mathrm{Cl}_{2}(\mathrm{~kJ} / \mathrm{mol})$ & $\mathrm{I}_{\mathrm{sp}}$ acetone $(\mathrm{kJ} / \mathrm{mol})$ \\
\hline Bt & $174 \pm 4$ & $0.06 \pm 0.01$ & $16.7 \pm 1$ & - \\
CSBt $0.1 / 1$ & $112 \pm 3$ & $0.41 \pm 0.03$ & $14.3 \pm 1$ & - \\
CSBt 0.5/1 & $54 \pm 2$ & $0.92 \pm 0.04$ & $11.6 \pm 0.5$ & $11.2 \pm 0.7$ \\
CSBt $1 / 1$ & $49 \pm 1$ & $0.93 \pm 0.03$ & $11.2 \pm 0.5$ & $10.4 \pm 0.5$ \\
CS & $46 \pm 1$ & $0.98 \pm 0.02$ & $10.2 \pm 0.5$ & $10.2 \pm 0.4$ \\
\hline
\end{tabular}

disappearance of high energy sites on Bt hidden by CS. This significant decrease in the $\gamma_{s}^{\mathrm{d}}$ value of CSBt is due to the CS long chains coating clay surface (Fig. 8). Bilgiç, Yazıcı, Karakehya, Çetinkaya, Singh and Chehimi [55] found that for organo-bentonite, the surface energy of the clay decreased with the increase of polymer incorporation. This was explained by the cation exchanged energetic sites of clay covered by organic polymers. Indeed, the increase of functional groups reduces the values of $\gamma_{s}^{d}[56,57]$.

In order to obtain information about morphology at the molecular scale, the nanomorphological index obtained with cycloheptane probe (Cy7) was determined. The lower nanomorphological index obtained with $\mathrm{Cy} 7$ on Bt corresponds to size exclusion effect. The linear alkane is able to insert partially into sheets of clay, whereas a cyclic alkane is excluded [58]. For the CSBt composites, the $I_{M}(\chi t)$ values are close to 1 as for CS testifying the disappearance of the surface roughness, which corresponds to the coating of Bt surface by CS.
By injecting acidic and amphoteric probes such as dichloromethane and acetone, the specific interaction parameter, $\mathrm{I}_{\mathrm{sp}}$, was also determined. The value of $\mathrm{I}_{\mathrm{sp}}$ obtained with acidic dichloromethane decreases from 16.7 to $11.2 \mathrm{~kJ} / \mathrm{mol}$ as the $\mathrm{CS} / \mathrm{Bt}$ ratio increases and tends towards $10.2 \mathrm{~mJ} / \mathrm{mol}$, the CS $\mathrm{I}_{\mathrm{sp}}$ value. This variation testifies of the coating of the silanols or aluminols groups (amphoteric groups) or double-linked oxygen groups (basic character) [59-61]. Acetone, with a strong basic character, could not be eluted through the Bt chromatographic column even at $383 \mathrm{~K}$ testifying of the strong acidic character of the Bt surface. This fact could be explained by the interaction of acetone probe with silanols or aluminols groups (amphoteric groups), present in clay surface. Similar results were obtained with montmorillonite at $383 \mathrm{~K}$ [30] and attapulgite at $403 \mathrm{~K}$ [62].

\subsubsection{IGC at finite concentration (IGC-FC)}

4.6.2.1. Study of desorption isotherms. The studied samples were submitted to IGC-FC using an apolar probe, n-octane, which is mainly sensitive to surface morphology and a polar one, isopropanol, more sensitive to surface functionality.

The desorption isotherm was computed from a chromatogram when the probe monolayer is reached at the solid surface, according to the ECP method.

In Table 4 are reported values of specific surface areas, obtained by IGC-FC, using octane and isopropanol, and compared to those obtained by nitrogen adsorption.

It is observed that whatever the sample, the specific surface areas measured with nitrogen are higher than those measured with noctane C8 and isopropanol IP probes. This deviation was already observed in the study of CS/montmorillonite bionanocomposites [30] and thermal treatment of attapulgite [63]. This fact can be attributed to the structure of probes, polarity and encumbrance.

Moreover, the specific surface areas obtained using C8 are greater than those measured by IP probe, this finding can be explained by the more irreversible character of IP adsorption compared to that of C8. As described in the theoretical section above, the amount of high energetic sites can be evaluated through the peak of thermodesorption. The values of the irreversibility indexes $\mathrm{I}_{\text {irr }}$ calculated by integration of thermodesorption peaks are presented in Table 4. It is observed that 

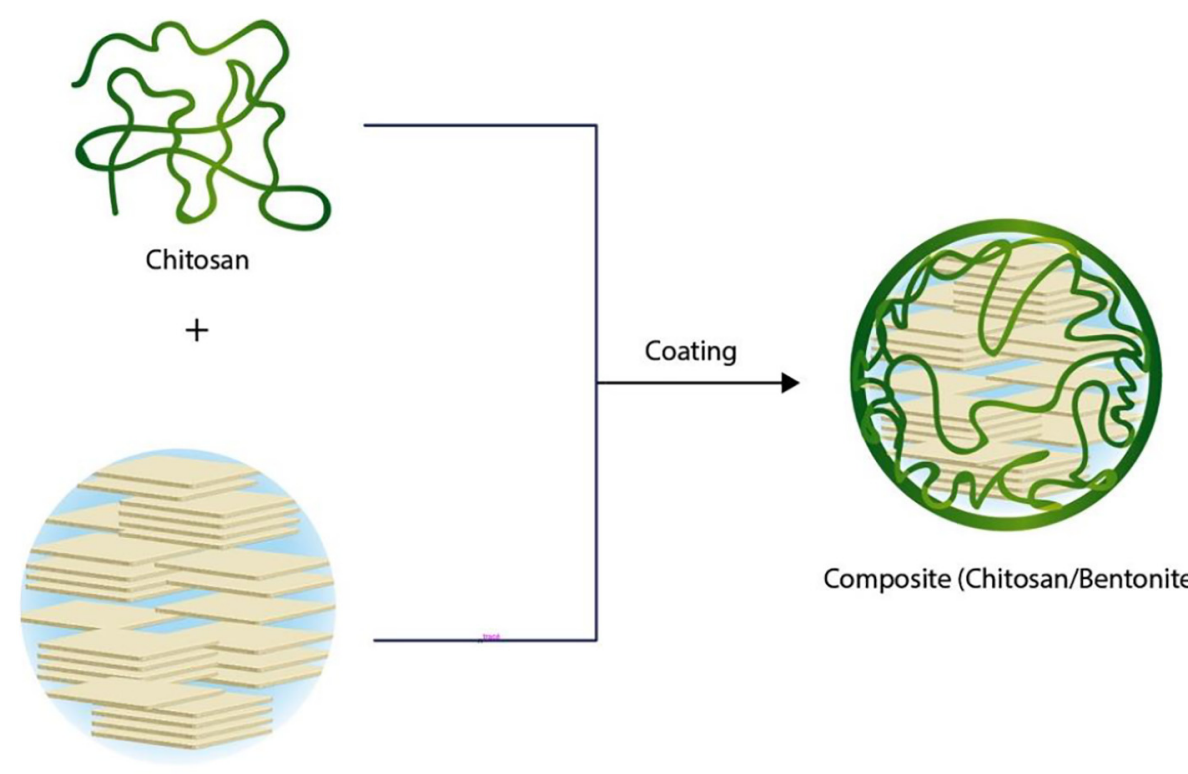

Composite (Chitosan/Bentonite)

Bentonite

Fig. 8. Schematic structure of CS biopolymer coated Bt clay.

Table 4

Values of specific surface areas ( $\mathrm{a}_{\mathrm{BET}}$ ) and irreversibility $\left(\mathrm{I}_{\mathrm{irr}}\right)$ indexes obtained on the studied samples by $\mathrm{N}_{2}$ adsorption and IGC-FC with n-octane and isopropanol probes.

\begin{tabular}{|c|c|c|c|c|c|}
\hline \multirow[t]{3}{*}{ Samples } & \multirow{3}{*}{$\begin{array}{l}\mathrm{N}_{2}(77 \mathrm{~K}) \\
\overline{\mathrm{a}_{\mathrm{BET}}\left(\mathrm{m}^{2} / \mathrm{g}\right)}\end{array}$} & \multicolumn{4}{|l|}{ ICG-FC } \\
\hline & & \multicolumn{2}{|l|}{ C8 (333 K) } & \multicolumn{2}{|l|}{$\mathrm{IP}(313 K)$} \\
\hline & & $\mathrm{a}_{\mathrm{BET}}\left(\mathrm{m}^{2} / \mathrm{g}\right)$ & $\mathrm{I}_{\mathrm{irr}}$ & $\mathrm{a}_{\mathrm{BET}}\left(\mathrm{m}^{2} / \mathrm{g}\right)$ & $\mathrm{I}_{\text {irr }}$ \\
\hline $\mathrm{Bt}$ & 74.39 & $66.8 \pm 2.2$ & $6.4 \pm 0.3$ & $54.1 \pm 4.2$ & $37.50 \pm 3.3$ \\
\hline CSBt $0.1 / 1$ & 58.03 & $52.9 \pm 3.4$ & $2.5 \pm 0.3$ & $46.3 \pm 2.8$ & $22.2 \pm 1.6$ \\
\hline CSBt $0.5 / 1$ & 12.47 & $9.3 \pm 1.6$ & $1.4 \pm 0.1$ & $9.1 \pm 1.9$ & $18.2 \pm 0.9$ \\
\hline CSBt $1 / 1$ & 5.42 & $3.9 \pm 1.3$ & $1.4 \pm 0.1$ & $3.6 \pm 1.1$ & $12.2 \pm 0.5$ \\
\hline $\mathrm{CS}$ & 4.10 & $1.5 \pm 0.2$ & $0.2 \pm 0.1$ & $0.9 \pm 1.3$ & $4.2 \pm 0.3$ \\
\hline
\end{tabular}

the irreversibility indexes of the polar probe obtained for CSBt composites are higher than those obtained using $\mathrm{C} 8$, reflecting a higher irreversible adsorption of the IP probe compared to the C8. The part of probe irreversibly adsorbed is not taken into account in the specific surface area calculation and contributes to under-estimate it.

In addition, whatever the probe, nitrogen, $\mathrm{C} 8$, and IP, the values of the specific surface areas decrease with increasing of CS/Bt mass ratio to get closer to the values obtained for CS alone. Simultaneously, it can be observed that whatever the probe used, the irreversibility index in CSBt composites, decrease with the increase of CS/Bt mass ratio. The variation of all these parameters (specific surface areas and
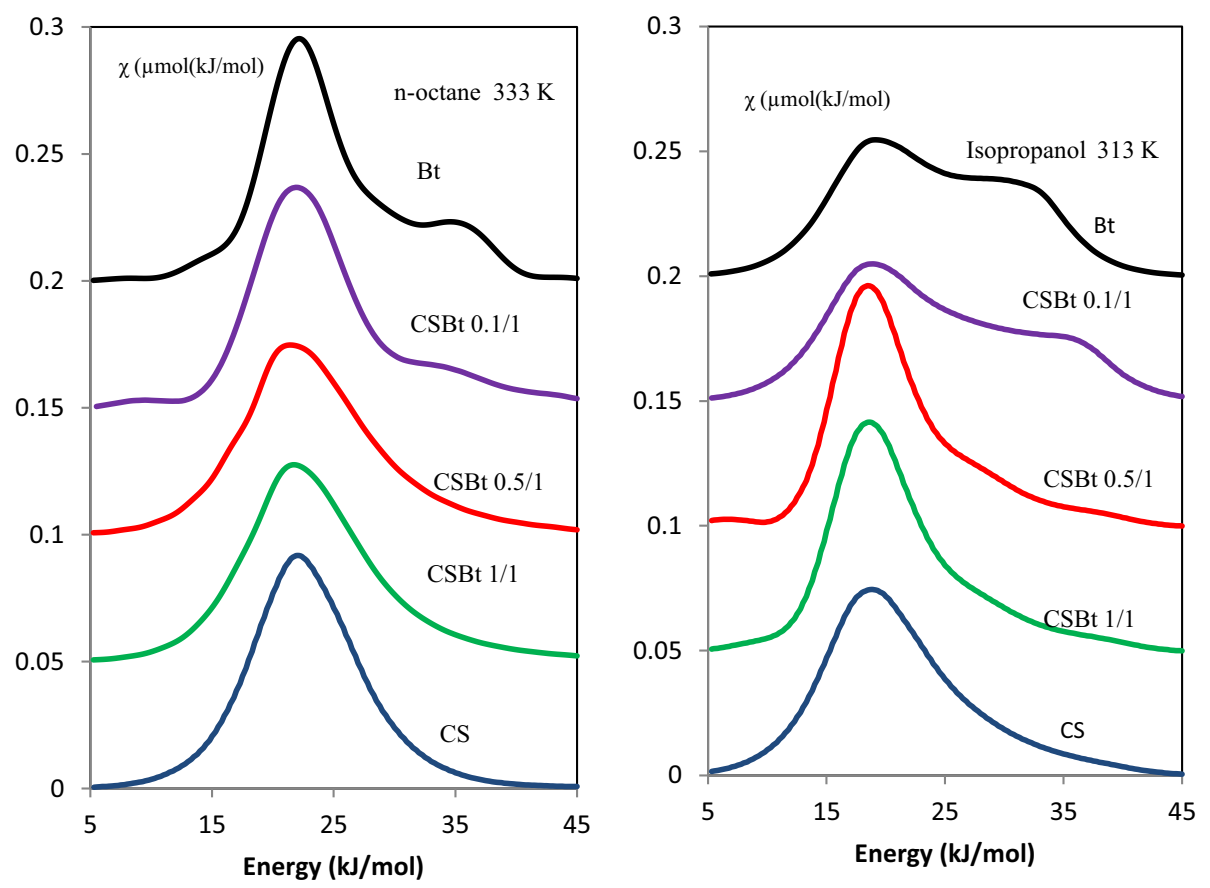

Fig. 9. Distribution functions of the adsorption energies of the n-octane (333 K) and isopropanol (313 K) for CS, Bt and CSBt composites. 
irreversibility index), which tend to those of CS alone for both organic probes, are correlated. The increase of the CS/Bt ratio leads to a smoother surface indicated by an $\mathrm{a}_{\mathrm{BET}}$ decrease and simultaneously a disappearance of high energy sites emphasized by the $\mathrm{I}_{\text {irr }}$ values decrease. These surface properties changes can be attributed to a covering of the Bt surface with CS, characterized by a non-porous surface.

Moreover, as showed by the specific surface area, or the $\mathrm{I}_{\mathrm{irr}}$, the ratio $1 / 1$ is not enough to entirely recover the Bt surface. All these values obtained with the $1 / 1$ composite remain higher than those obtained with CS alone.

4.6.2.2. Variation of the surface heterogeneity. The adsorption energy distribution functions calculated with Rudziński, Jagiełło and Grillet [40] model and developed by Balard [37] noted DFRJ, obtained with C8 and IP probes are presented in Fig. 9. The DFRJ of C8 obtained on Bt clay is bimodal. The first peak, at $22 \mathrm{~kJ} / \mathrm{mol}$ more intense than the second one, $36 \mathrm{~kJ} / \mathrm{mol}$, can be attributed to the adsorption of the probe on low energy sites on the flat surface. The second peak can reveal adsorption on high energy sites located in lateral surface between the layers of Bt clay. The DFRJs obtained for CSBt composites are monomodal. The disappearance of the shoulder towards high energies testifies that morphology modification takes place after Bt covering with CS, as it has been shown by XPS and BET surface analysis.

As expected, the IP DFRJs are different than these obtained with C8, once IP develops specific interactions with the surface while C8 exchanges dispersive ones. For Bt, the IP DFRJ shows two peaks with similar intensities, a first peak with a maximum observed at $19 \mathrm{~kJ} / \mathrm{mol}$ due to the interaction of the IP probe with domains bearing siloxane bridges, and a second one around $33 \mathrm{~kJ} / \mathrm{mol}$, attributed to the sites of stronger interaction among them silanol and aluminol functions of Bt clay.

Considering the DFRJs of IP on CSBt composites beads, a progressive disappearance of the second peak at high energies is noted from the 0.1 / $1 \mathrm{CS} / \mathrm{Bt}$ ratio up to obtain a monomodal DFRJs for the $1 / 1 \mathrm{CS} / \mathrm{Bt}$ ratio similar to the CS one. This observation is another proof indicating that the sites of Bt clay characterized by two kinds of adsorption energies sites have been covered by CS characterized by only one type of adsorption sites.

The heterogeneity of studied solids surface was estimated from the asymmetry of the adsorption energy distribution functions and the calculation of the heterogeneity index $\mathrm{I}_{\text {hete }}$ (Eq. (10)). It was evaluated for the same organic probes, C8 (apolar) and IP (polar) (Table 5).

$I_{\text {hete }}$ decreases clearly from 23 to $10 \%$ for C8 probe, and from 39 to $16 \%$ for IP probe upon CS incorporation. This suggests the progressive covering of the Bt surface by CS. The polymer chains of CS mask the slits between sheets or structure defects highlighted by interaction with C8 and high energy sites in lateral surfaces or silanols/aluminols groups that can interact with IP.

\section{Conclusion}

CSBt composites beads were prepared with different CS/Bt ratios by dropwise addition of liquid slurry containing $\mathrm{CS}$ and $\mathrm{Bt}$ to a $\mathrm{NaOH}$ solution. The CSBt composites were characterized in terms of surface chemical composition, textural analysis, microscopic morphology and surface

Table 5

Values of heterogeneity indexes $\mathrm{I}_{\text {hete }}$ measured by IGC-FC for C8 and IP probes on the studied composites.

\begin{tabular}{lll}
\hline & $\mathrm{I}_{\text {hete }}(\mathrm{C} 8) \% 333 \mathrm{~K}$ & $\mathrm{I}_{\text {hete }}(\mathrm{IP}) \% 313 \mathrm{~K}$ \\
\hline Bts & $23 \pm 2.8$ & $39 \pm 4.5$ \\
CSBt $0.1 / 1$ & $20 \pm 1.9$ & $37 \pm 4.1$ \\
CSBt $0.5 / 1$ & $14 \pm 1.3$ & $17 \pm 1.1$ \\
CSBt $1 / 1$ & $10 \pm 0.9$ & $16 \pm 1.0$ \\
CS & $3 \pm 0.3$ & $14 \pm 0.8$
\end{tabular}

energy which confirmed the strong interaction between Bt clay and CS biopolymer.

The XRD diffractograms confirmed the distortion of peaks corresponding to Bt after CS introduction. XPS showed that $\mathrm{C}$ and $\mathrm{N}$ major elements of CS increase in surface of CSBt with increase of mass ratio CS/ Bt which shows the covering of the surface of Bt by CS. The BET analysis of N2 adsorption showed a drastic decrease of the specific surface area with increase of mass ratio CS/Bt, emphasizing a smoothing of Bt surface due to the Bt coverage with CS.

IGC was used to investigate the surface properties of the studied raw materials and CSBt composites. The IGC-ID showed that the dispersive contribution to the surface energy $\gamma_{s}^{d}$ of CSBt decreased considerably compared to Bt due to the CS chains covering the clay surface. The $I_{M}$ $(\chi \mathrm{t})$ values of CSBt composites are close to 1 testifying the disappearance of the surface roughness. Whereas the specific interaction parameter, determined by injection of polar probes, indicates that Bt exhibits a strong interaction with acidic and basic probes due to the amphoteric character of Bt surface clay. However, CS incorporation induced a change in the surface acidity, the CSBt composites being less acidic, probably due to lower exposure of silanol groups in the Bt surface.

By IGC-FC, the distribution functions obtained with n-octane, a probe sensitive to the surface morphology are monomodal and symmetrical for all composites as for CS, indicating that CS affects significantly the surface morphology of $\mathrm{Bt}$, showing two peaks.

The distribution functions of CSBt composites with isopropanol probe confirm also the decrease in the number of the high energetic sites due to Bt clay coverage with CS.

In conclusion, the Bt surface coverage with CS affects drastically the Bt surface properties. These composites will be of interest to adsorb some anionic dyes and heavy metals.

\section{CRediT authorship contribution statement}

Soufiane Bensalem: Investigation, Writing - original draft. Boualem Hamdi: Methodology. Sylvie Del Confetto: Data curation. Rachel Calvet: Supervision, Validation.

\section{Acknowledgements}

The authors thank Ministry of Higher Education and Scientific Research of Algeria (PNE program) and IMT Mines Albi (Ecole des Mines d'Albi Carmaux) for providing financial support for this research undertaking.

\section{References}

[1] C. Bothiraja, U. Thorat, A. Pawar, K. Shaikh, Chitosan coated layered clay montmorillonite nanocomposites modulate oral delivery of paclitaxel in colonic cancer, Mater. Technol. 29 (sup3) (2014) B120-B126, https://doi.org/10.1179/1753555714Y. 0000000174.

[2] C. Viseras, C. Aguzzi, P. Cerezo, M. Bedmar, Biopolymer-clay nanocomposites for controlled drug delivery, Mater. Sci. Technol. 24 (9) (2008) 1020-1026, https:// doi.org/10.1179/174328408X341708.

[3] F. Chivrac, E. Pollet, M. Schmutz, L. Avérous, Starch nano-biocomposites based on needle-like sepiolite clays, Carbohydr. Polym. 80 (1) (2010) 145-153, https://doi. org/10.1016/j.carbpol.2009.11.004.

[4] A.B. Neji, M. Jridi, M. Nasri, R.D. Sahnoun, Preparation, characterization, mechanical and barrier properties investigation of chitosan-kaolinite nanocomposite, Polym. Test. 84 (2020) 106380, https://doi.org/10.1016/j.polymertesting.2020.106380.

[5] L. Alves, E. Ferraz, J. Gamelas, Composites of nanofibrillated cellulose with clay minerals: a review, Adv. Colloid Interf. Sci. 272 (2019), 101994, https://doi.org/10.1016/ j.cis.2019.101994.

[6] F.M. Dardir, A.S. Mohamed, M.R. Abukhadra, E.A. Ahmed, M.F. Soliman, Cosmetic and pharmaceutical qualifications of Egyptian bentonite and its suitability as drug carrier for Praziquantel drug, Eur. J. Pharm. Sci. 115 (2018) 320-329, https://doi. org/10.1016/j.ejps.2018.01.041.

[7] M.R. Abukhadra, N.M. Refay, A.M. El-Sherbeeny, A.M. Mostafa, M.A. Elmeligy, Facile synthesis of bentonite/biopolymer composites as low-cost carriers for 5-fluorouracil drug; equilibrium studies and pharmacokinetic behavior, Int. J. Biol. Macromol. 141 (2019) 721-731, https://doi.org/10.1016/j.ijbiomac.2019.09.057. 
8] M.R. Abukhadra, A. Adlii, B.M. Bakry, Green fabrication of bentonite/chitosan@ cobalt oxide composite (BE/CH@ $\mathrm{Co}$ ) of enhanced adsorption and advanced oxidation removal of Congo red dye and $\mathrm{Cr}$ (VI) from water, Int. J. Biol. Macromol. 126 (2019) 402-413, https://doi.org/10.1016/j.ijbiomac.2018.12.225.

[9] B. Krajewska, Application of chitin-and chitosan-based materials for enzyme immobilizations: a review, Enzym. Microb. Technol. 35 (2-3) (2004) 126-139, https://doi. org/10.1016/j.enzmictec.2003.12.013.

[10] R. Jayakumar, D. Menon, K. Manzoor, S. Nair, H. Tamura, Biomedical applications of chitin and chitosan based nanomaterials-a short review, Carbohydr. Polym. 82 (2) (2010) 227-232, https://doi.org/10.1016/j.carbpol.2010.04.074.

[11] J. Pérez-Calderón, M.V. Santos, N. Zaritzky, Reactive RED 195 dye removal using chitosan coacervated particles as bio-sorbent: analysis of kinetics, equilibrium and adsorption mechanisms, J. Environ. Chem. Eng. 6 (5) (2018) 6749-6760, https://doi. org/10.1016/j.jece.2018.10.039.

[12] A. Varma, S. Deshpande, J. Kennedy, Metal complexation by chitosan and its derivatives: a review, Carbohydr. Polym. 55 (1) (2004) 77-93, https://doi.org/10.1016/ j.carbpol.2003.08.005.

[13] V.E. Santo, M.E. Gomes, J.F. Mano, R.L. Reis, Chitosan-chondroitin sulphate nanoparticles for controlled delivery of platelet lysates in bone regenerative medicine, J. Tissue Eng. Regen. Med. 6 (S3) (2012) s47-s59, https://doi.org/10.1002/term.1519.

[14] E. Vunain, A. Mishra, B. Mamba, Dendrimers, mesoporous silicas and chitosan-based nanosorbents for the removal of heavy-metal ions: a review, Int. J. Biol. Macromol. 86 (2016) 570-586, https://doi.org/10.1016/j.ijbiomac.2016.02.005.

[15] T. Anirudhan, S. Rijith, Synthesis and characterization of carboxyl terminated poly (methacrylic acid) grafted chitosan/bentonite composite and its application for the recovery of uranium (VI) from aqueous media, J. Environ. Radioact. 106 (2012) 8-19, https://doi.org/10.1016/j.jenvrad.2011.10.013.

[16] S.S. Ray, M. Okamoto, Polymer/layered silicate nanocomposites: a review from preparation to processing, Prog. Polym. Sci. 28 (11) (2003) 1539-1641, https://doi.org/ 10.1016/j.progpolymsci.2003.08.002.

[17] M.L.P. Dalida, A.F.V. Mariano, C.M. Futalan, C.-C. Kan, W.-C. Tsai, M.-W. Wan, Adsorptive removal of $\mathrm{Cu}$ (II) from aqueous solutions using non-crosslinked and crosslinked chitosan-coated bentonite beads, Desalination 275 (1-3) (2011) 154-159, https://doi.org/10.1016/j.desal.2011.02.051.

[18] W.-C. Tsai, S. Ibarra-Buscano, C.-C. Kan, C.M. Futalan, M.LP. Dalida, M.-W. Wan, Removal of copper, nickel, lead, and zinc using chitosan-coated montmorillonite beads in single-and multi-metal system, Desalin. Water Treat. 57 (21) (2016) 9799-9812, https://doi.org/10.1080/19443994.2015.1035676.

[19] W.S. Wan Ngah, N.F.M. Ariff, A. Hashim, M.A.K.M. Hanafiah, Malachite green adsorption onto chitosan coated bentonite beads: isotherms, kinetics and mechanism, Clean-Soil, Air, Water 38 (4) (2010) 394-400, https://doi.org/10.1002/clen. 200900251.

[20] K.-H. Liu, T.-Y. Liu, S.-Y. Chen, D.-M. Liu, Drug release behavior of chitosanmontmorillonite nanocomposite hydrogels following electrostimulation, Acta Biomater. 4 (4) (2008) 1038-1045, https://doi.org/10.1016/j.actbio.2008.01.012.

[21] S. Hua, H. Yang, W. Wang, A. Wang, Controlled release of ofloxacin from chitosanmontmorillonite hydrogel, Appl. Clay Sci. 50 (1) (2010) 112-117, https://doi.org/ 10.1016/j.clay.2010.07.012.

[22] H. Balard, D. Maafa, A. Santini, J. Donnet, Study by inverse gas chromatography of the surface properties of milled graphites, J. Chromatogr. A 1198 (2008) 173-180, https://doi.org/10.1016/j.chroma.2008.05.012.

[23] J. Gamelas, E. Ferraz, F. Rocha, An insight into the surface properties of calcined kaolinitic clays: the grinding effect, Colloids Surf. A Physicochem. Eng. Asp. 455 (2014) 49-57, https://doi.org/10.1016/j.colsurfa.2014.04.038.

[24] B. Hamdi, T. Gottschalk-Gaudig, H. Balard, E. Brendlé, N. Nedjari, J.-B. Donnet, Aging process of some pyrogenic silica samples exposed to controlled relative humidities: part II: evolution of their surface properties studied using inverse gas chromatography, Colloids Surf. A Physicochem. Eng. Asp. 488 (2016) 46-51, https://doi.org/10. 1016/j.colsurfa.2015.10.018.

[25] L. Boudriche, R. Calvet, B. Hamdi, H. Balard, Effect of acid treatment on surface properties evolution of attapulgite clay: an application of inverse gas chromatography, Colloids Surf. A Physicochem. Eng. Asp. 392 (1) (2011) 45-54, https://doi.org/10. 1016/j.colsurfa.2011.09.031.

[26] A. Tamayo, J. Kyziol-Komosinska, M.J. Sánchez, P. Calejas, J. Rubio, M.F. Barba, Characterization and properties of treated smectites, J. Eur. Ceram. Soc. 32 (11) (2012) 2831-2841, https://doi.org/10.1016/j.jeurceramsoc.2011.12.029.

[27] A. Aşkın, Surface characterization of sepiolite by inverse gas chromatography, Chromatographia $61(11-12)$ (2005) 625-631, https://doi.org/10.1365/s10337005-0558-z.

[28] B. Shi, S. Zhao, L. Jia, L. Wang, Surface characterization of chitin by inverse gas chromatography, Carbohydr. Polym. 67 (3) (2007) 398-402, https://doi.org/10.1016/j. carbpol.2006.06.012.

[29] E. Papirer, E. Brendle, H. Balard, C. Vergelati, Inverse gas chromatography investigation of the surface properties of cellulose, J. Adhes. Sci. Technol. 14 (3) (2000) 321-337, https://doi.org/10.1163/156856100742627.

[30] S. Bensalem, B. Hamdi, S. Del Confetto, M. Iguer-Ouada, A. Chamayou, H. Balard, R. Calvet, Characterization of chitosan/montmorillonite bionanocomposites by inverse gas chromatography, Colloids Surf. A Physicochem. Eng. Asp. 516 (2017) 336-344, https://doi.org/10.1016/j.colsurfa.2016.12.051.

[31] P. Coimbra, M.S. Coelho, J.A. Gamelas, Surface characterization of polysaccharide scaffolds by inverse gas chromatography regarding application in tissue engineering, Surf. Interface Anal. 51 (11) (2019) 1070-1077, https://doi.org/10.1002/sia. 6693.

[32] J.A. Gamelas, J. Pedrosa, A.F. Lourenço, P.J. Ferreira, Surface properties of distinct nanofibrillated celluloses assessed by inverse gas chromatography, Colloids Surf. A Physicochem. Eng. Asp. 469 (2015) 36-41.
[33] F. Mohammadkazemi, R. Aguiar, N. Cordeiro, Improvement of bagasse fiber-cement composites by addition of bacterial nanocellulose: an inverse gas chromatography study, Cellulose 24 (4) (2017) 1803-1814, https://doi.org/10.1007/s10570-0171210-4.

[34] A. Voelkel, B. Strzemiecka, K. Adamska, K. Milczewska, Inverse gas chromatography as a source of physiochemical data, J. Chromatogr. A 1216 (10) (2009) 1551-1566, https://doi.org/10.1016/j.chroma.2008.10.096.

[35] S. Mohammadi-Jam, K. Waters, Inverse gas chromatography applications: a review, Adv. Colloid Interf. Sci. 212 (2014) 21-44, https://doi.org/10.1016/j.cis.2014.07.002.

[36] J.R. Conder, C.L. Young, Physicochemical Measurement by Gas Chromatography, John Wiley \& Sons, 1979.

[37] H. Balard, Estimation of the surface energetic heterogeneity of a solid by inverse gas chromatography, Langmuir 13 (5) (1997) 1260-1269, https://doi.org/10.1021/ la951526d.

[38] G.M. Dorris, D.G. Gray, Adsorption of n-alkanes at zero surface coverage on cellulose paper and wood fibers, J. Colloid Interface Sci. 77 (2) (1980) 353-362, https://doi. org/10.1016/0021-9797(80)90304-5.

[39] H. Balard, E. Brendlé, E. Papirer, Determination of the acid-base properties of solid surfaces using inverse gas chromatography: advantages and limitations, acid-base interactions: relevance to adhesion, Sci. Technol. 2 (2000) 299-316.

[40] W. Rudziński, J. Jagiełło, Y. Grillet, Physical adsorption of gases on heterogeneous solid surfaces: evaluation of the adsorption energy distribution from adsorption isotherms and heats of adsorption, J. Colloid Interface Sci. 87 (2) (1982) 478-491, https://doi.org/10.1016/0021-9797(82)90345-9.

[41] N.S. Kumar, M. Suguna, M.V. Subbaiah, A.S. Reddy, N.P. Kumar, A. Krishnaiah, Adsorption of phenolic compounds from aqueous solutions onto chitosan-coated perlite beads as biosorbent, Ind. Eng. Chem. Res. 49 (19) (2010) 9238-9247, https://doi. org/10.1021/ie901171b.

[42] W.S.W. Ngah, N.F.M. Ariff, M.A.K.M. Hanafiah, Preparation, characterization, and environmental application of crosslinked chitosan-coated bentonite for tartrazine adsorption from aqueous solutions, Water Air Soil Pollut. 206 (1-4) (2010) 225-236, https://doi.org/10.1007/s11270-009-0098-5.

[43] M. Darder, M. Colilla, E. Ruiz-Hitzky, Biopolymer-clay nanocomposites based on chitosan intercalated in montmorillonite, Chem. Mater. 15 (20) (2003) 3774-3780, https://doi.org/10.1021/cm0343047.

[44] E.L. Foletto, D.S. Paz, A. Gündel, Acid-activation assisted by microwave of a Brazilian bentonite and its activity in the bleaching of soybean oil, Appl. Clay Sci. 83 (2013) 63-67, https://doi.org/10.1016/j.clay.2013.08.017.

[45] C. De Oliveira, M. Rocha, A. Da Silva, L. Bertolino, Characterization of bentonite clays from Cubati, Paraíba (Northeast of Brazil), Cerâmica 62 (363) (2016) 272-277. https://doi.org/10.1590/0366-69132016623631970.

[46] S.-F. Wang, L. Shen, W.-D. Zhang, Y.-J. Tong, Preparation and mechanical properties of chitosan/carbon nanotubes composites, Biomacromolecules 6 (6) (2005) 3067-3072, https://doi.org/10.1021/bm050378v.

[47] I. Amaral, P. Granja, M. Barbosa, Chemical modification of chitosan by phosphorylation: an XPS, FT-IR and SEM study, J. Biomater. Sci. Polym. Ed. 16 (12) (2005) 1575-1593, https://doi.org/10.1163/156856205774576736.

[48] C.D. Wagner, C.J. Powell, J.W. Allison, J.R. Rumble, NIST X-ray photoelectron spectroscopy database 1 , Version 2 (1997).

[49] J. Diosa, J.C. Poveda-Jaramillo, F. Ramirez-Rodríguez, M. Mesa, Modeling surface chemistry and adsorption behavior of biomimetic chitosan/silica hybrid materials, J. Mater. Res. Technol. 9 (4) (2020) 8092-8103, https://doi.org/10.1016/j.jmrt. 2020.05.100.

[50] E. Padilla-Ortega, M. Darder, P. Aranda, R.F. Gouveia, R. Leyva-Ramos, E. Ruiz-Hitzky, Ultrasound assisted preparation of chitosan-vermiculite bionanocomposite foams for cadmium uptake, Appl. Clay Sci. 130 (2016) 40-49, https://doi.org/10.1016/j. clay.2015.11.024.

[51] M.N. Belgacem, A. Blayo, A. Gandini, Surface characterization of polysaccharides, lignins, printing ink pigments, and ink fillers by inverse gas chromatography, J. Colloid Interface Sci. 182 (2) (1996) 431-436, https://doi.org/10.1006/jcis.1996.0484.

[52] N. Cordeiro, J. Silva, C. Gomes, F. Rocha, Bentonite from Porto Santo Island, Madeira archipelago: surface properties studied by inverse gas chromatography, Clay Miner. 45 (1) (2010) 77-86, https://doi.org/10.1180/claymin.2010.045.1.77.

[53] E. Picard, H. Gauthier, J.-F. Gérard, E. Espuche, Influence of the intercalated cations on the surface energy of montmorillonites: consequences for the morphology and gas barrier properties of polyethylene/montmorillonites nanocomposites, J. Colloid Interface Sci. 307 (2) (2007) 364-376, https://doi.org/10.1016/j.jcis.2006.12.006.

[54] B. Hamdi, Z. Kessaissia, J.-B. Donnet, T.K. Wang, Characterization of surface energy and morphology of two natural fillers: Kieselguhr and bentonite, Annales de Chimie Science des Matériaux, Elsevier 2000, pp. 481-494, https://doi.org/10.1016/S01519107(00)80023-9.

[55] C. Bilgiç, D.T. Yazıcı, N. Karakehya, H. Cetinkaya, A. Singh, M.M. Chehimi, Surface and interface physicochemical aspects of intercalated organo-bentonite, Int. J. Adhes. Adhes. 50 (2014) 204-210, https://doi.org/10.1016/j.ijadhadh.2014.01.033.

[56] M. Mravčáková, K. Boukerma, M. Omastová, M.M. Chehimi, Montmorillonite/polypyrrole nanocomposites. The effect of organic modification of clay on the chemical and electrical properties, Mater. Sci. Eng. C 26 (2-3) (2006) 306-313, https://doi. org/10.1016/j.msec.2005.10.044.

[57] D. Topaloğlu Yazıcı, Investigating the surface properties of polymer-coated clay by IGC, Surf. Interface Anal. 42 (6-7) (2010) 974-977, https://doi.org/10.1002/sia. 3291.

[58] M.-P. Comard, R. Calvet, J.A. Dodds, H. Balard, Coupling of inverse gas chromatography at infinite dilution (IGC-ID) with a controlled modification of a solid surface, J. Chromatogr. A 969 (1-2) (2002) 93-96, https://doi.org/10.1016/S0021-9673(02) 00207-8. 
[59] K. Bendada, B. Hamdi, L. Boudriche, H. Balard, R. Calvet, Surface characterization of reservoir rocks by inverse gas chromatography: effect of a surfactant, Colloids Surf. A Physicochem. Eng. Asp. 504 (2016) 75-85, https://doi.org/10.1016/j. colsurfa.2016.05.047.

[60] T. Benkacem, B. Hamdi, A. Chamayou, H. Balard, R. Calvet, Physicochemical characterization of a diatomaceous upon an acid treatment: a focus on surface properties by inverse gas chromatography, Powder Technol. 294 (2016) 498-507, https:// doi.org/10.1016/j.powtec.2016.03.006.

[61] A. Ashori, N. Cordeiro, M. Faria, Y. Hamzeh, Effect of chitosan and cationic starch on the surface chemistry properties of bagasse paper, Int. J. Biol. Macromol. 58 (2013) 343-348, https://doi.org/10.1016/j.ijbiomac.2013.04.056.
[62] L. Boudriche, B. Hamdi, Z. Kessaissia, R. Calvet, A. Chamayou, J.A. Dodds, H. Balard, An assessment of the surface properties of milled attapulgite using inverse gas chromatography, Clay Clay Miner. 58 (2) (2010) 143-153, https://doi.org/10.1346/CCMN 2010.0580201.

[63] L. Boudriche, R. Calvet, B. Hamdi, H. Balard, Surface properties evolution of attapulgite by IGC analysis as a function of thermal treatment, Colloids Surf. A Physicochem. Eng. Asp. 399 (2012) 1-10, https://doi.org/10.1016/j.colsurfa.2012. 02.015 . 